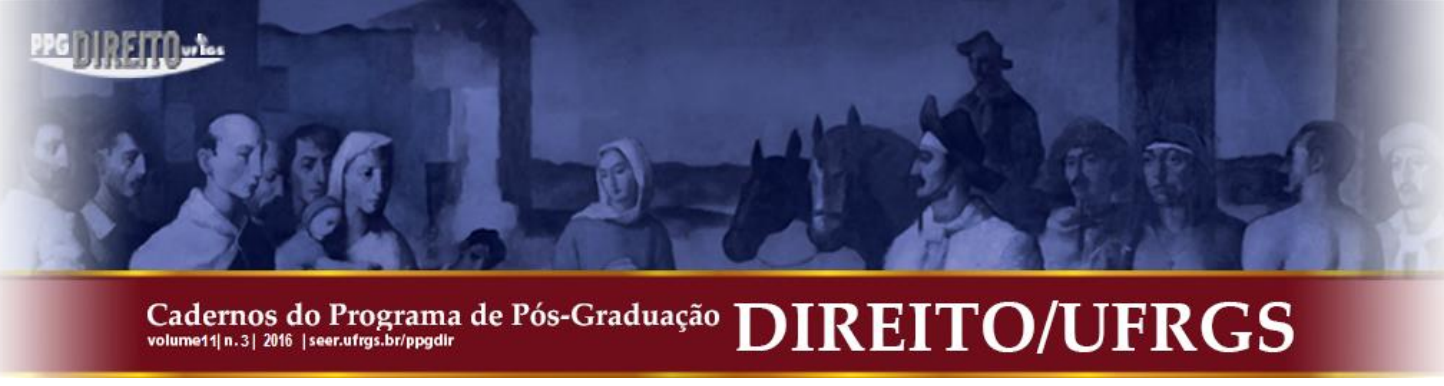

\title{
O ASSÉDIO MORAL AO IDOSO PELO DESRESPEITO AO DIREITO PERSONALÍSSIMO DE ENVELHECER COM DIGNIDADE: UMA AFRONTA AO PRINCÍPIO DA DIGNIDADE HUMANA
}

\author{
THE MORAL HARASSMENT THE ELDERLY BY THE INFRINGEMENT PERSONALITY \\ RIGHTS WITH DIGNITY: AN AFFRONT TO PRINCIPLE OF HUMAN DIGNITY
}

\section{Lucas Yuzo Abe Tanaka* \\ Cleide Aparecida Gomes Rodrigues Fermentão**}

\begin{abstract}
RESUMO: O princípio da Dignidade da Pessoa Humana é o que fundamenta a Constituição Federal de 1988, pelo que as demais normas e princípios devem retirar o seu fundamento. Consagrou que é dever do Estado, da família e da sociedade em auxiliar os idosos para o seu pleno desenvolvimento de sua dignidade, garantindo-se assim o direito à vida e o respeito ao seu direito personalíssimo. $\mathrm{O}$ abandono ao idoso pela família, pelo Estado e pela sociedade, pode configura-se não apenas como um assédio moral, mas também um desrespeito ao Princípio da Dignidade Humana, e ainda ao seu direito personalíssimo de envelhecer. Assim, o presente trabalho sustenta a relevo do Estado, da sociedade e da família no papel de abrigar a dignidade da pessoa humana deste individuo. Para tanto, no trabalho cientifico, foi empregado o método teórico que versa na pesquisa de obras e artigos circulares específicos que tratam sobre o tema. Ademais analisa a situação dos idosos frente ao abandono, o assédio moral como uma violação à dignidade humana dos idosos.
\end{abstract}

PALAVRAS-CHAVE: Assédio Moral. Envelhecer. Direitos da Personalidade. Dignidade Humana.
ABSTRACT: The principle of Human Dignity is the foundation of the Federal Constitution of 1988, so, any other norms and principles should draw from its foundation. It established to the state, family and society the duty of helping the elderly to the full development of their dignity, thus guaranteeing the right to life and respect for their personal right. The abandonment of the elderly by his family, the state and society, is set up not only as moral harassment, but also a disregard for the principle of human dignity, and even to the personal right to grow old. Thus, this study supports the role of harboring the human dignity of the individual by the state, the society and the family. Therefore, in this scientific work, we used the theoretical method which deals in the works of research and specific circular articles that deal with the subject. Furthermore the situation of the elderly against abandonment and moral harassment is analyzed as a violation of human dignity of the elderly.

KEYWORDS: Moral Harassment. Aging. Personality Rights. Human Dignity.

SUMÁRIO: Introdução. 1 Os Direitos da Personalidade. 2 Da Dignidade Humana. 3 A Tutela Jurídica dos Idosos. 4 O Envelhecimento e os Direitos da Personalidade. 5 O Assédio Moral ao Idoso causando Dor e Constrangimento, pelo Desrespeito ao Direito Personalíssimo de Envelhecer com Dignidade. Considerações Finais. Referências.

\section{INTRODUÇÃO}

O número de pessoas idosas tem crescido consideravelmente, não somente no Brasil, e as dificuldades que estas enfrentam em seu Direito personalíssimo de viver com dignidade, as tornam vulneráveis, sentindo-se envelhecer como folhas amarelecidas que são pisoteadas e lançadas ao vento. As mãos trêmulas cansadas, e os olhos turvos já não enxergam, e no peito

\footnotetext{
* Mestrando em Ciências Jurídicas pelo Centro Universitário de Maringá (Unicesumar), Paraná. Professor do curso de Direito do Centro Universitário de Maringá (Unicesumar), Paraná.

${ }^{* *}$ Doutora em Direito pela Universidade Federal do Paraná (UFPR). Professora do Programa de Pós-Graduação em Direito do Centro Universitário de Maringá (Unicesumar), Paraná.
} 


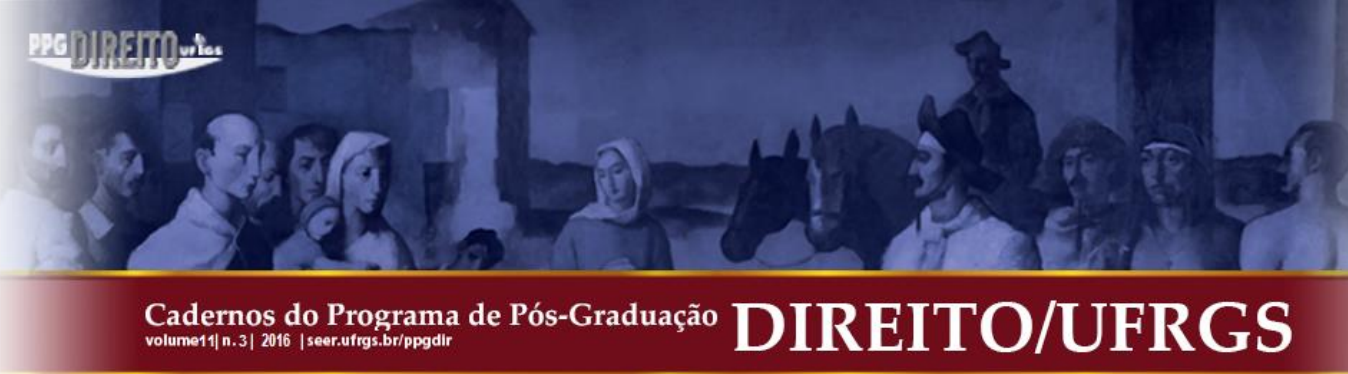

a dor, um grito sufocado pela indiferença da família, da sociedade e do Estado. Eis o assédio moral.

O assédio moral faz com que o idoso sinta-se abandonado e frágil. Nada mais the resta. O desprezo ao idoso por parte da família é o gotejar de dor que lhe retira o desejo de viver. A indiferença da sociedade e do Estado leva o idoso a sentir-se improdutivo e impotente. A axiologia explica a ausência de valores morais e sociais, onde não se valoriza a experiência de vida. Envelhecer é sentir a vida escoar lentamente, e já mortos pela ausência de dignidade, esperam pela morte.

A realidade social tem se revestido de nova roupagem. A ciência contribuiu e as pessoas passaram a viver mais tempo. E, a longevidade tem um peso social e econômico crescente e preocupante para o Estado. Envelhecer com saúde e com respeito, e principalmente com dignidade é o mínimo que se espera do Estado.

A Constituição Federal de 1988 tem como fundamento o princípio da Dignidade Humana e o Estatuto do Idoso consagrou o direito de envelhecer como um Direito personalíssimo. Porém, nem sempre tal Direito é respeitado. Os idosos enfrentam o desrespeito à sua dignidade, e, apesar de fazerem parte da história e de tê-la construído com amor e dedicação, muitas vezes são esquecidos e desamparados, não apenas por seus familiares, mas pela sociedade e pelo Estado.

O presente artigo tem como mister fazer uma análise do Direito de envelhecer com dignidade, diante do aumento de pessoas longevas, da falta de estrutura do Estado e, da indiferença emocional com que as famílias tem tratado os seus idosos.

E questiona-se: é possível pensar em assédio moral aos longevos pelos membros da família, que deveriam proporcionar aos mesmos um convívio caloroso regado pelo afeto e pelo respeito? É possível pensar em assédio moral aos idosos por parte do Estado ao não valorizá-los pelas experiências ao longo da vida e não protegê-los com ações públicas que lhes garanta uma vida digna?

Tais problematizações serão enfrentadas com a análise do direito da personalidade do idoso, do direito à dignidade humana como pessoa humana, da Constituição Federal e do Estatuto do idoso. Além das normas faz-se também preciso analisar a vulnerabilidade do idoso no que se refere ao físico, psíquico e emocional.

Os idosos têm a seu favor, além do Princípio constitucional de proteção à dignidade humana, a garantia de seus direitos pelo Estatuto do Idoso (Lei $\mathrm{n}^{\circ} 10.741$, de $1^{\mathrm{o}}$ de outubro de 


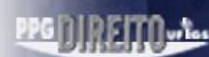

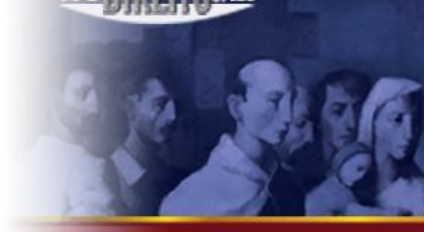 \\ Cadernos do Programa de Pós-Graduação volume11|n.3| 2016 |seer.utrgs.br/ppgdit}

2003.). Tanto a Constituição Federal como as leis infraconstitucionais protegem a vulnerabilidade dos idosos, razão pela qual necessitam de especial proteção, tanto do Estado como da sociedade, e ainda, como dever da família, o amparo aos idosos.

Cabe ao Estado, a sociedade, aos cidadãos, e principalmente a família efetivarem os direitos ao idoso, a fim de assegurar o seu Direito personalíssimo de vida digna, para que assim, o mesmo possa atingir sua felicidade, e isso só é possível se os laços afetivos, seus valores, suas necessidades e dificuldades, estiverem sendo respeitados. Assim, o objetivo deste artigo é discorrer sobre o direito de envelhecer de forma digna, para a proteção dos direitos da personalidade e da dignidade humana do idoso, buscando entender o mundo da longevidade, e as necessidades para uma vida plena.

\section{OS DIREITOS DA PERSONALIDADE}

Para analisar os direitos da personalidade, faz-se necessário verificar a noção de pessoa, tendo em vista que para, necessita primeiramente responder o que é homem, e, homem é pessoa, e afirma-se que a noção de pessoa é uma criação da teologia cristã, pelo que o conceito "persona" alterou-se substancialmente e passou a designar uma realidade substantiva; passou a ser uma verdadeira categoria ontológica, assim afirma-se que a noção de pessoa é uma criação da teologia cristã (GONÇALVES, 2008, p. 19).

Para que se faça um conceito de pessoa, são necessárias as seguintes características:

a) que o gênero presente na definição corresponda à categoria de ente, tal como aqui a consideramos;

b) que as diferenças específicas que integram o conceito manifestem estas três notas: a particular intensidade do acto de ser, fundamento da ipseidade; a respectividade ôntica ou abertura relacional constitutiva; e a dimensão tridimensional, criadora da própria unidade ontológica (COSTA, 2008, p. 63).

Ademais, Dray (2006, p. 05), considera que

A ideia de pessoa não está necessariamente, quanto à sua origem, associada aos propósitos da sua tutela. Como sublinha Menezes Cordeiro, a idéia de pessoa impôsse, no Direito, como instrumento técnico para assegurar a organização econômica e social, tornando operacional a figura de troca e, por essa via, do contrato e da propriedade. 


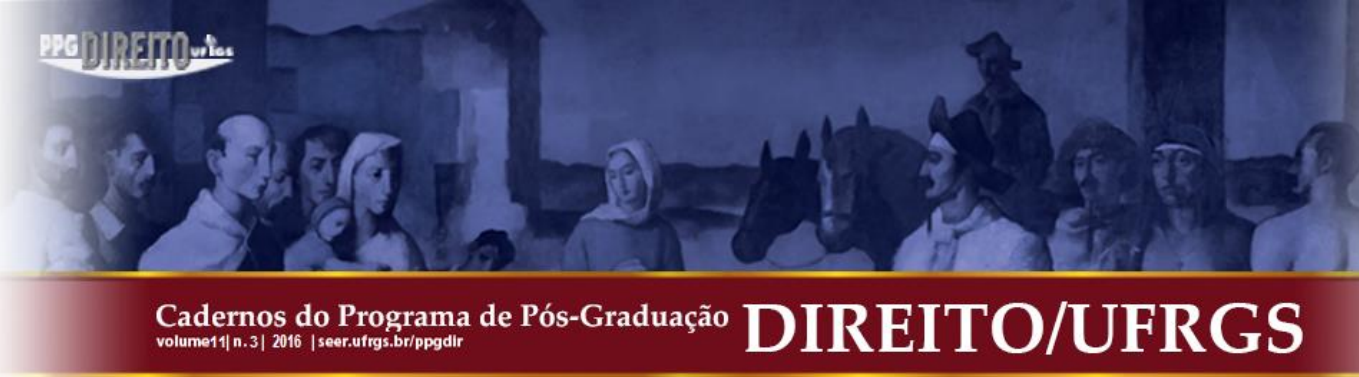

O conceito de pessoa (COSTA, 2008, p. 64) “é aquele ente que, em virtude da especial intensidade do seu acto de ser, autopossui a sua própria realidade ontológica, em abertura relacional constitutiva e dimensão realizacional unitiva", pelo que fica compreendido que a pessoa tem autonomia quanto ao ser, tem autoconsciência, comunicação e autotranscende.

Conceituar personalidade torna-se difícil, ao se analisar que alguns autores tratam-na como análoga o conceito de pessoa e personalidade. No entanto, para Diogo Gonçalves Costa há uma diferença entre pessoa e personalidade, esta cuida de qualidades do ente que determinam o modo de ser da pessoa, podendo ser naturais ou adquiridas, correspondendo, ainda, a categoria das relações: "a pessoa é constitutivamente relacional” (COSTA, 2008, p. 64), sendo que ao exprimir o melhor conceito sobre personalidade, o mesmo autor (COSTA, 2008, p. 68) afirma que "é o conjunto das qualidades e relações que determinam a pessoa em si mesma e em função da participação na ordem do ser, de forma única e singular".

A construção da teoria do direito da personalidade

se confunde com a construção relativa dos direitos fundamentais, mas adquire força a partir da consagração da dignidade da pessoa humana como valor fundante dos Estados Democráticos, o que coloca o ser humano como centro referencial dos ordenamentos jurídicos. (...) a lógica fundante dos direitos da personalidade é a tutela da dignidade da pessoa humana (CANTALI. 2009. p. 61).

Ademais, é no pensamento filosófico dos gregos, que se encontram contribuições para a teoria dos direitos da personalidade, sendo que tanto no pensamento grego clássico e pósclássico, o homem foi considerado como origem e finalidade da lei e do direito, ganhando novo sentido a capacidade jurídica de todo homem e dos seus inerentes direitos da personalidade (DE SOUZA, 1995, p. 46 e 47).

O direito da personalidade para De Plácido e Silva vem “do latim 'personalitas', de persona (pessoa), propriamente, significar o conjunto de elementos, que se mostram próprios ou inerentes à pessoa, formando ou constituindo um individuo que, em tudo, morfológica, fisiológica e psicologicamente se diferencia de qualquer outro" (DE PLÁCIDO E SILVA, p. 1035).

Direitos da personalidade são os direitos dedicados a proteger a dignidade da pessoa humana, preservando, principalmente de ataques de outros indivíduos (GOMES, 2000, p. 63).. E podem ser aqueles direitos inerentes à pessoa humana, tais como a vida, a honra e a liberdade, dentre outros, ou seja, são direitos essenciais ao desenvolvimento da pessoa 
a dignidade era tida como a qualidade que, por ser inerente ao ser humano, o distinguia das demais criaturas, no sentido de que todos os seres humanos são dotados da mesma dignidade, noção esta que se encontra, por sua vez, intimamente ligada à noção da liberdade pessoal que cada indivíduo (o Homem como ser livre e responsável por seus atos e seu destino), bem como à ideia de que todos os seres humanos, no que diz com a sua natureza, são iguais em dignidade (SARLET, 2009. p. 32).

A dignidade da pessoa humana no pensamento filosófico e na antiguidade clássica era verificada em regra, a partir da posição social em que o individuo se encontrava, e ainda, pela posição hierárquica em que se encontrava perante sua comunidade, sob a qual dizia-se que havia uma quantificação de dignidade, pelo que admitia-se, assim, a existência de pessoas mais dignas e menos dignas (SARLET, 2009. p. 32).

Tem-se como uma das mais remotas idéias de dignidade humana a que está estabelecida na bíblia, onde Deus cria o homem segundo a sua imagem e semelhança. $\mathrm{O}$ cristianismo trouxe um valor próprio do ser, ou seja, um valor intrínseco a si mesmo, pelo que não se pode transformá-lo em um mero objeto ou até mesmo um instrumento (SARLET, 2009. p. 32).

O cristianismo por meio dos ensinamentos de São Tomas de Aquino (AQUINO, 1890), foi explicado a semelhança do ser humano a Deus, de modo a dotá-lo de autonomia, de tal forma tornando o ser humano livre por sua própria natureza e essência. Entendeu-se que o ser humano deve ser entendido como um fim e nunca como um meio para se obter um resultado. Em outras palavras, diferenciando coisas de pessoas (KANT, 1980, p. 135-140).

Conforme imperativo categórico de Kant (KANT, 1980, P. 135) "Age de forma que trates a humanidade, tanto na tua pessoa, como de qualquer outro, sempre também como $\mathrm{m}$ fim e nunca unicamente um meio", tratando-se, assim, de que o próprio homem tem um valor intrínseco em si.

Nesse mesmo sentido Ingo Wolfgang salienta que "a dignidade, como qualidade intrínseca do ser humano é irrenunciável e inalienável, constituindo elemento que qualifica o ser humano" (SARLET, 2009, p. 47), ou seja, não pode a dignidade ser retirada do ser humano por tratar-se de um direito inerente do individuo.

"A ideia do valor intrínseco da dignidade da pessoa humana deita raízes já no pensamento clássico e no ideário cristão" (SARLET, 2009. p. 31), e que apesar de sua projeção histórica, foi apenas na segunda década do século XX que começou a aparecer nos documentos jurídicos, sendo que o seu primeiro apontamento foi na Constituição do México 


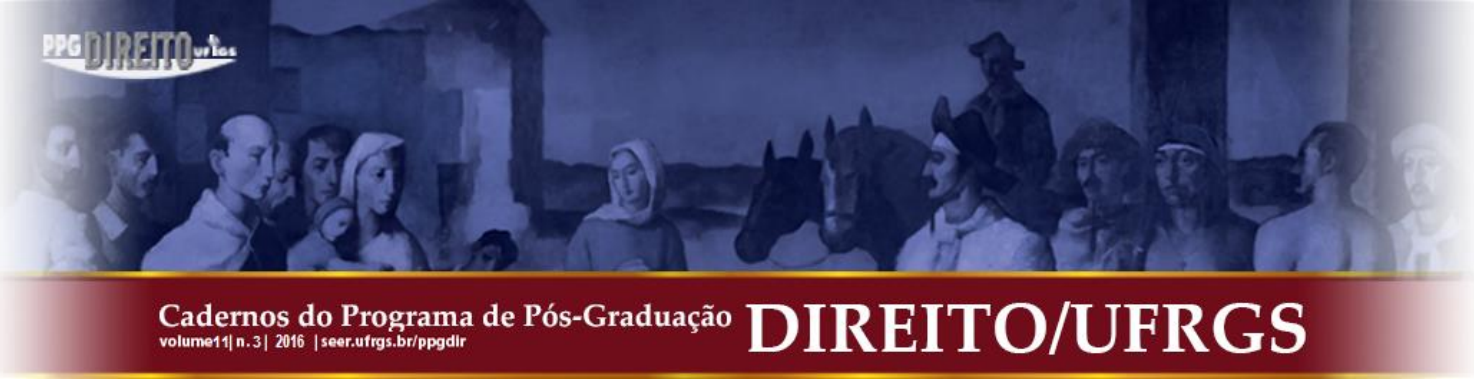

em 1917 e com a Constituição alemã da República de Weimar em 1919.

Há de se destacar que é reconhecido que a ascensão da dignidade humana se deu por meio do direito constitucional alemão e "de acordo com o Tribunal, a dignidade humana se situa no ápice do sistema constitucional, representando um valor supremo, um bem absoluto à luz do qual outros dispositivos devem ser interpretados” (BARROSO, 2012. p. 21).

Com efeito, está na Constituição Federal a base sobre a qual se assentam os princípios de maior expressividade no sistema jurídico brasileiro. Os valores e sobrevalores que a Carta Maior proclama hão de ser partilhado entre os cidadãos, não como quimeras ou formas utópicas simplesmente desejadas e conservadas como relíquias na memória social, mas como algo pragmaticamente realizável, apto, a qualquer instante, para cumprir seu papel demarcatório, balizador, autêntica fronteira nos hemisférios da nossa cultura. A propósito, vale a afirmação peremptória de que o direito positivo, visto como um todo, na sua organização entitativa, nada mais almeja do que prepara-se, aparelhar-se, pré-ordenar-se para implantá-los (CARVALHO, 2009, p. 141).

A Constituição Federal de 1988, no art. $1^{\text {a }}$ inciso III, consagrou o principio da dignidade da pessoa humana, concomitantemente estabelecendo no seu Art. 230 a defesa da dignidade ao individuo idoso, ao obrigar o estado, a sociedade e a família na inclusão da pessoa anciã na comunidade, buscando seu bem-estar. Há de destacar ainda que a constituição portuguesa, em relação ao princípio da dignidade humana, também proclama a proteção a todas as pessoas indistintamente, ou seja, todos os seres humanos, pessoas, são titulares deste princípio, não cabendo qualquer discriminação (GOMES, 2009, p.27).

A dignidade da pessoa humana é o princípio supremo da constituição federal servindo como base para todo o ordenamento jurídico, para tanto, é o principio constitucional mais relevante, é ele que traça a diretriz para a harmonização dos princípios (NUNES, 2002, p. 55). Trata-se, portanto, de um princípio, não se restringindo a uma simples declaração ou até mesmo um postulado filosófico. E, assim, não se pode afirmar que a dignidade possui apenas força declaratória ou se refere a uma norma abstrata lançado no ordenamento jurídico brasileiro, é um alicerce para todo o ordenamento jurídico.

Ainda, a característica fundamental do princípio da dignidade humana

que o sobreleva em importância e significado é que ele assegura um minimum de respeito ao homem só pelo fato de ser homem, uma vez que todos os homens são dotados por natureza de igualdade e "tem direito a levar uma vida digna de seres humanos". Vale dizer: o respeito à pessoa humana realiza-se independentemente da comunidade, grupo ou classe social a que aquela pertença (FARIAS, 2000, p. 60). 


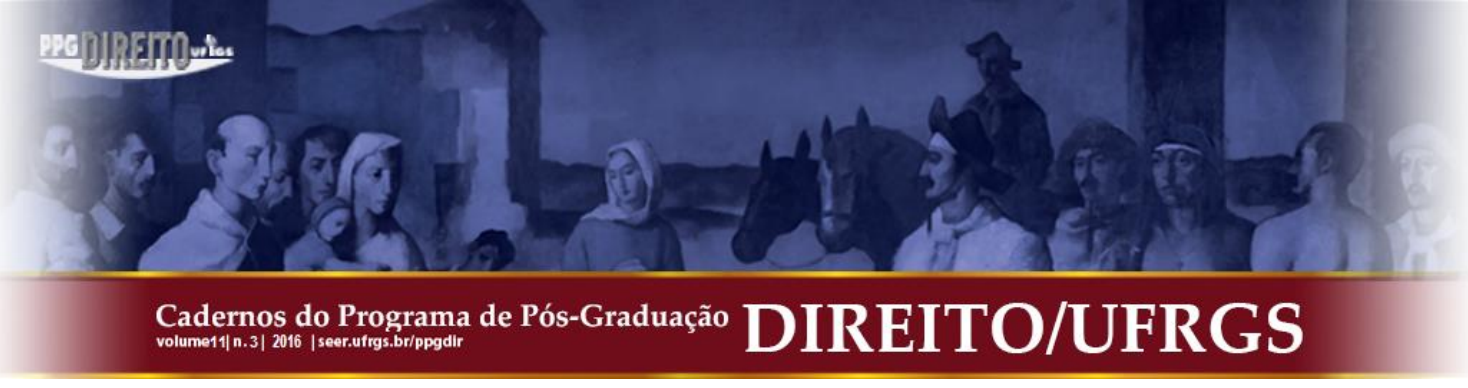

O princípio da dignidade humana, por ser a base e o fundamento das normas jurídicas, coordena-as, bem como aos seus princípios. Possui, ainda, por se tratar de um princípio norteador, dupla natureza, indicando como as demais normas devem ser feitas e aplicadas, de forma que nenhuma delas pode ferir a dignidade da pessoa humana, justamente por ser a norma suprema da Constituição Federal (FERMENTÃO; JÚNIOR, 2012, p. 317).

A dignidade da pessoa humana não é apenas um direito, mas mais do que um direito, posto que é a base em que se fundamenta os direitos da personalidade, pelo que os demais direitos devem estar em conformidade com a dignidade humana que é reconhecida como um valor supremo no ordenamento jurídico.

\section{A TUTELA JURÍDICA DOS IDOSOS}

A Declaração Universal dos Direitos do Homem de 1948, mesmo que de forma tímida, já dispunha sobre a proteção aos idosos, em especial ao direito ao envelhecimento, na qual em seu artigo XXV, item 1, estabelece que:

Todo o homem tem direito a um padrão de vida capaz de assegurar a si e a sua família saúde e bem-estar, inclusive alimentação, vestuário, habitação, cuidados médicos e os serviços sociais indispensáveis, e direito à segurança em caso de desemprego, doença, invalidez, viuvez, velhice ou outros casos de perda dos meios de subsistência em circunstâncias fora de seu controle.

No entanto, apenas no ano de 1982, em âmbito mundial houve certa preocupação com o idoso, na qual a Organização das Nações Unidas, na cidade de Viena, promoveu uma assembleia com o objetivo precípuo de debater o envelhecimento e a necessidade de constituir metas voltadas à inclusão dos idosos na sociedade, e também buscar a promoção de sua tutela. (COSSI, 2015, p. 581).

Faz-se necessário, ainda, um breve histórico das normas Constitucionais acerca do direito dos idosos, sendo que as Constituições de 1824 e 1891 nada dispuseram sobre as pessoas idosas, ambas foram omissas acerca do tema. Já a Constituição de 1934 foi a primeira a tratar sobre o direito dos idosos, no entanto tratou apenas sobre direito previdenciário, dentro do capítulo sobre a ordem econômica e social. Seguindo a mesma linha da 


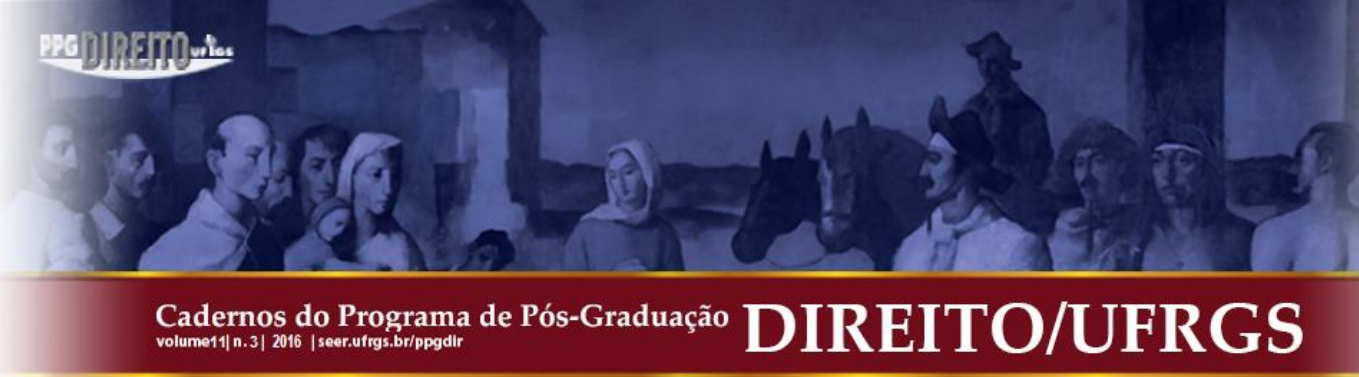

Constituição de 1934, as Constituições de 1937, 1946 e 1967, também trataram apenas sobre à proteção da velhice pela previdência (BARLETTA, 2010, p. 79).

Somente com a Constituição Federal de 1988 que os idosos tiveram uma proteção mais ampla, e, inclusive considerada como um direito fundamental, sendo que, nos termos do artigo 230, consagrou o dever da família, Estado e sociedade de auxiliar as pessoas idosas para proteger sua dignidade e bem-estar, garantindo-lhes, portanto, o direito à vida.

Segundo Roberto Senise Lisboa

O princípio da solidariedade familiar previsto no texto constitucional (art. $1^{\circ}$, III c/c
os arts. $3^{\circ}$, I, 226, caput, 227,229 e 230 da CF) viabiliza a adoção de postura mais
flexível e consentânea com o direito de família da pós-modernidade. Reconhece-se
que tanto o nascituro como a criança, o adolescente e o adulto possuem direitos
decorrentes das relações havidas da constituição de entidades familiares. Além
disso, contempla-se em favor do adulto que tem pelo menos sessenta anos de idade
um regime legal protetivo dos seus interesses, assim como se procedeu com a
previsão de normas tutelares dos interesses das crianças e adolescentes (LISBOA,
2010, P. 298).

Posteriormente à Constituição Federal, implantou-se uma política nacional de proteção ao idoso por intermédio da Lei 8.842/1994, na qual se assegurou alguns direitos sociais ao idoso, permitindo-lhe a promover sua autonomia, integração e participação na sociedade (GAMA, 2008, P. 276). Esta lei adotou os seguintes princípios para a proteção da terceira idade: a) a garantia dos direitos inerentes à cidadania e da sua participação na comunidade; b) a defesa do direito à vida do idoso, do seu bem-estar e da prevalência do princípio da dignidade do idoso; e a proibição da discriminação do idoso.

No ano de 2003, instituiu-se o Estatuto do Idoso, por meio da Lei 10.741/2003, por meio do qual se reconheceram os direitos fundamentais inerentes à pessoa idosa, consagrando inúmeras prerrogativas e direitos às pessoas de mais de 60 anos. Verifica-se que o Estatuto do Idoso adotou o critério etário para a identificação do idoso, ou seja, é a pessoa com idade igual ou maior de 60 anos, conforme dispõe o seu artigo $1^{\circ}$. Tal estatuto trata de um microssistema, consagrando normas para a efetivação das normas de proteção ao idoso, cabendo não apenas a família, mas ao Estado e a sociedade a concretização destes direitos.

Com a Lei 10.741/2003 reconheceu-se os direitos fundamentais à pessoa idosa garantindo todos os ensejos e facilidades para proteção e preservação da sua integridade física e psíquica, garantindo assim, a proteção da dignidade humana, fundamento supremo estacando pela Constituição Federal de 1988, dando-lhe, assim, oportunidade de participar

Cadernos do Programa de Pós-Graduação em Direito PPGDir./UFRGS | Edição Digital | Porto Alegre | Volume XI | Número 3 | 2016 | P.148-167 


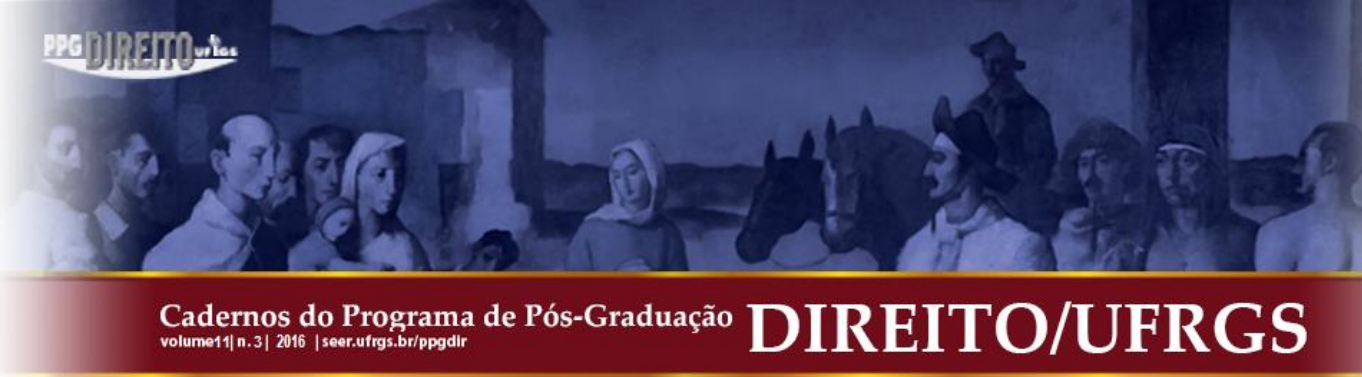

incessantemente na sociedade, posto que "o idoso sofre a constante ameaça de subtração de sua autonomia devido às naturais contingências da velhice, o que implicaria a mutação de sua condição jurídica de pessoa capaz para incapaz” (GAMA, 2008, p. 276).

$\mathrm{O}$ artigo $8^{\circ}$ do estatuto estabelece como direito personalíssimo o envelhecimento, sendo, portanto, um direito social, pelo que é essencial que o idoso tenha uma velhice digna, com qualidade de vida. É imprescindível que o idoso tenha assegurado e respeitado o seu direito à vida, a saúde física e psíquica, à intimidade e privacidade, as relações com a comunidade, como qualquer outra pessoa, e, segundo Gama (2008, p. 280) "nessa dimensão situa-se o cuidado como valor jurídico que, relativamente ao idoso, deve assegurar, em toda sua dimensão, o livre exercício do direito ao envelhecimento". O Estatuto do Idoso ainda assegura o direito a alimentos aos idosos nos seus artigos 11 a 14, lembrando que, a própria Constituição Federal em seu artigo 229, estabelece que os filhos maiores devem ajudar e amparar seus pais seja na velhice, carência ou enfermidade.

Verifica-se que houve um avanço enorme quanto a proteção dos idosos, não cabendo apenas à família a sua proteção, mas também a sociedade e ao Estado, bem como depreendese que é titular de todos os direitos personalíssimos, como qualquer outra pessoa, conferindolhe proteção própria por meio do Estatuto do Idoso.

\section{O ENVELHECIMENTO E OS DIREITOS DA PERSONALIDADE}

Segundo o dicionário Aurélio envelhecimento é o ato, processo ou efeito de envelhecer, ou ainda, processo ou procedimento para tornar velho ou como que envelhecido. O envelhecer representa para (HAYFLICK, 1997, p. 7) "a perda na função normal que ocorrem após a maturação sexual e continuam até a longevidade máxima para os membros de uma espécie".

O envelhecer significa que o ser humano esta sofrendo alterações físicas, psicológicas e sociais, pelo que são mudanças naturais, gradativas e paulatinas. Segundo SIMERMAN, “essas transformações são gerais, podendo se verificar em idade mais precoce ou mais avançada e em maior ou menor grau, de acordo com as características genéticas de cada indivíduo e, principalmente, com o modo de vida de cada um” (ZIMERMAN, 2000, p. 21), pelo que 


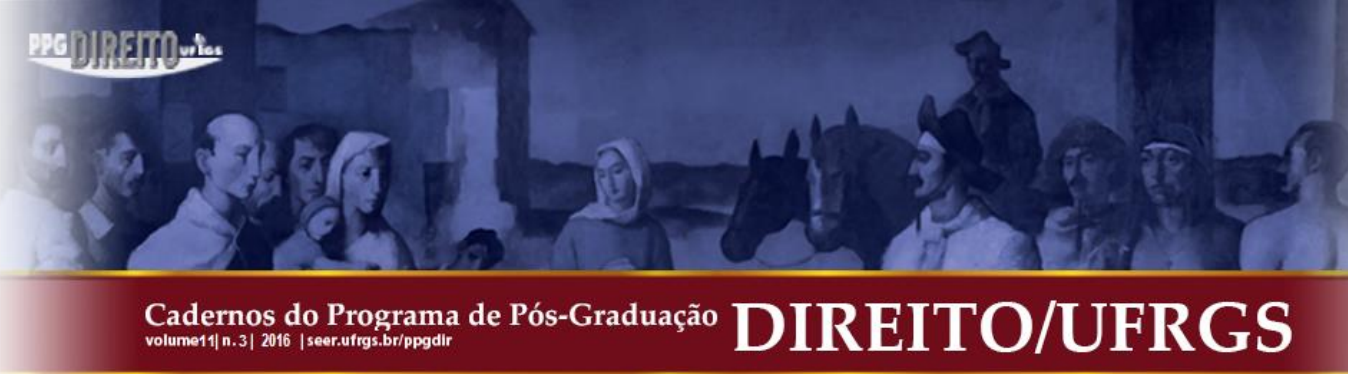

O envelhecer pode trazer muitas benesses, como a sabedoria advinda com a experiência, um maior conhecimento sobre a vida e sobre as pessoas. Também pode significar uma fase de maior aproveitamento da vida, com mais sossego e paz de espírito, colhendo os frutos do caminho percorrido. (TEIXEIRA; SÁ, 2007, p. 76).

Ainda, para Zimerman,

O velho é aquele que tem diversas idades: a idade do seu corpo, da sua história genética, da sua parte psicológica e da sua ligação com sua sociedade. É a mesma pessoa que sempre foi. Se foi um batalhador, vai continuar batalhando; se foi uma pessoa alegre, vai continuar alegrando; se foi uma pessoa insatisfeita, vai continuar insatisfeita; se foi ranzinza vai continuar ranzinza (ZIMERMAN, 2000, p. 19).

O idoso deve se sentir vivo em si mesmo. A sociedade e o Estado devem propiciar a estas pessoas o seu pleno desenvolvimento da personalidade, fazer com que o direito de envelhecer possa tornar-se um prazer, uma vida boa, posto que conforme Santo Tomas de Aquino (AQUINO, 2014, p. 36), “o prazer é o principal fim de todas as virtudes morais. Assim, é próprio das virtudes gerar felicidade sempre que seu objeto estiver presente, mas tristeza quando sentir necessidade dele".

Os filhos devem demonstrar o amor, gerar a felicidade aos pais envelhecidos, para que se assegure uma ampla e geral proteção de segurança nesta última idade, nesse último momento do seu viver, para o desenvolvimento pleno da personalidade e efetivação da dignidade humana. Compreende-se assim, umas das mais virtuosas ações do ser humano a assegurar-lhes maior proteção e segurança na última idade do seu processo de viver (SANTOS, 2001, p. 91),

Segundo Aquino (AQUINO. 2014. P. 50) “o homem é justo quando executa as obras justas; mas, quando não as executa, não cria as ações de virtude, nunca se esforçando para alcançá-las".

O idoso deve ser tratado pelo Estado, e, principalmente pelos indivíduos, de forma a lhe garantir a busca das suas maiores felicidades, tendo em vista, (ZIMERMAN, 2000, p. 22) “com o passar dos anos, o desgaste é inevitável. Sabe-se que a velhice não é uma doença, mas sim, uma fase na qual o ser humano fica mais suscetível a doenças", pelo que se deve buscar a sua máxima utilitarista, segundo a qual

O homem íntegro é aquele que se esforça por elevar a soma total de felicidade (a sua mais a dos outros), e a sociedade justa é aquela que busca elevar essa soma total a seu valor máximo. Em segundo lugar, o maximante, na visão da maioria dos 


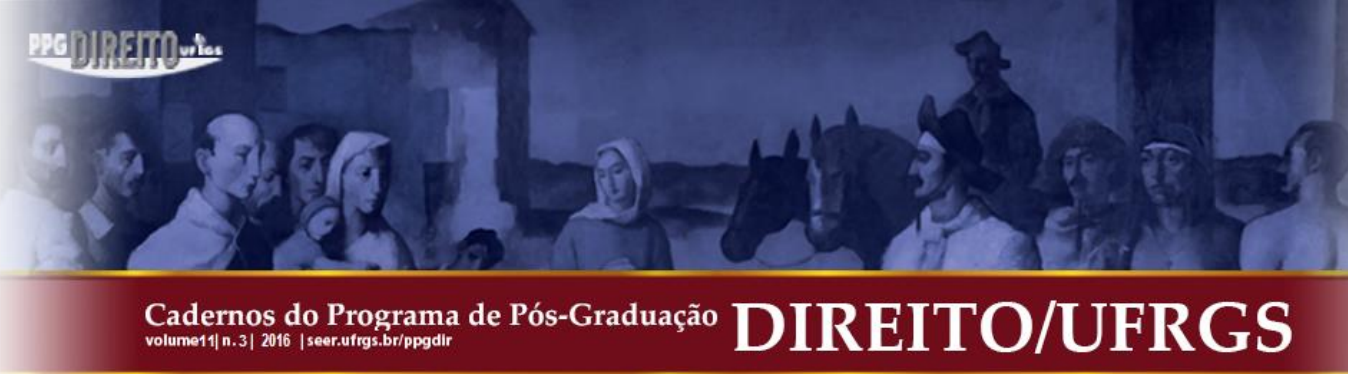

utilitaristas, não é um estado psicológico especifico, como o êxtase ou a euforia, mas sim o mais amplo conceito possível de satisfação. Atinge-se o máximo de felicidade, ou utilidade, quando as pessoas (ou criaturas) são capazes de satisfazer suas preferencias, quaisquer que sejam estas, na máxima medida possível (Posner 2010, p. 63).

Cada idoso é uma pessoa diferente, pelo que, cada um tem sua peculiaridade necessitando de um programa pessoal, seja do Estado ou da família para pleno desenvolvimento da personalidade, sendo que (ZIMERMAN, 2000, p. 35) deve-se analisar sempre o seu passado, sua história bem como o seu presente, para que esta pessoa da terceira idade seja uma pessoa saudável, feliz e desenvolvido em sua personalidade, capaz de usar todas as suas potencialidades e, inclusive, a sua dignidade humana.

O Estatuto do Idoso consagrou o envelhecimento como um Direito da personalidade, cabendo ao Estado e aos cidadãos que o compõem, cuidar dos idosos, por serem mais suscetíveis de abalos psíquicos, físicos e sociais; de forma a proteger e efetivar os idosos na sua personalidade, de torná-los felizes e realizados em sua vida. Assim, resguarda-se o Direito à vida, à saúde, à liberdade o respeito e a dignidade humana ao idoso.

Como ferramenta na busca da dignidade do idoso, de um envelhecimento digno, o idoso deve contar com os relacionamentos, mantendo amizades, com a faculdade de sair, se divertir, passear, participar de grupos de terceira idade, e, principalmente o apoio da família para que sempre venha buscar a maior felicidade. O indivíduo, em sua essência, necessita se relacionar com outros seres humanos, como descreve Neri AL Capitanini MES (2004, p. 7191):

Desvela-se dos discursos que é por meio dos relacionamentos que o ser humano
estabelece e reconhece a presença do outro, presença essa imprescindível na
construção de sua existência, uma vez que é por meio do afeto e do carinho que se
sustenta uma amizade e se amplia uma relação. O desenvolvimento pessoal está
alicerçado no curso das relações sociais, sem as quais não é possível ao ser humano
se construir como ser existencial. Essas redes de suporte social contribuem para que
o indivíduo acredite que é cuidado, amado e valorizado, sentindo-se pertencente ao
grupo, no qual pode dar e receber apoio emocional e, portanto, significativas no
processo de envelhecer.

Insta salientar que a influência da família neste procedimento de busca da vida em paz, da felicidade, do desenvolvimento e da personalidade do idoso é de suma importância, não bastando apenas o aspecto financeiro, mas principalmente, o afeto, o carinho e o amor aquele que viu-se envelhecer em cada ruga, o tingir dos cabelos em neve. 


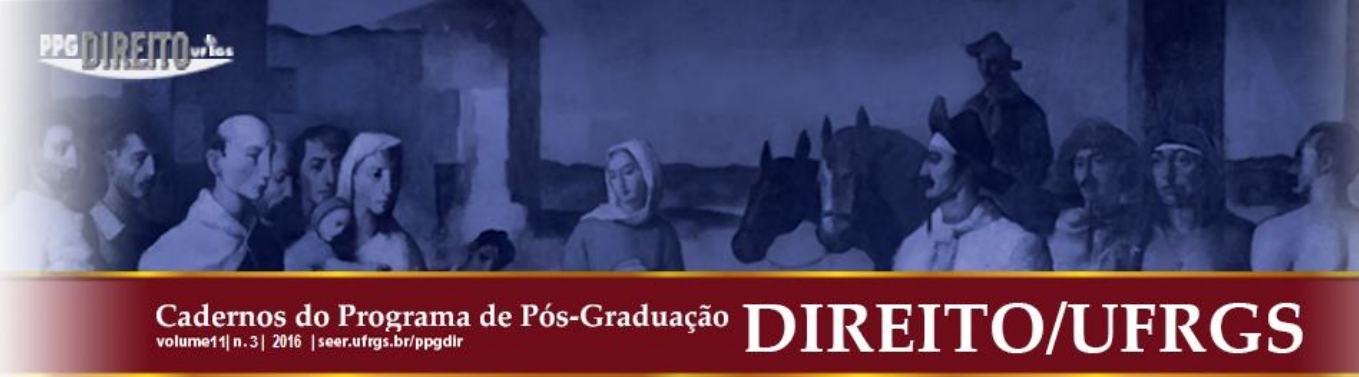

Os pés cansados da caminhada, os olhos turvos pela quantidade de dias vividos, as mãos trêmulas após uma vida de trabalho, a voz embargada pelas emoções vividas, e, um interior rico em experiências que a vida the proporcionou, torna seus passos lentos. Quantas perdas e conquistas, quantos sonhos vividos, idealizados, realizados e também frustrados. A vida foi lhe calando a alma, e, a indiferença das pessoas mais próximas, o desrespeito às necessidades basilares, o abandono, e muitas vezes os maus tratos, faz o idoso sentir-se só e infeliz, e um fardo pesado para a família, se sente inútil e indigno da vida.

\section{O ASSÉdIO MORAL AO IDOSO COMO CAUSA DOR E CONSTRANGIMENTO, PELO DESRESPEITO AO DIREITO PERSONALÍSSIMO DE ENVELHECER COM DIGNIDADE}

O assédio moral na esfera familiar existe com a finalidade de anular moralmente a pessoa assediada, levando à discriminação, à perda da auto-estima e até a doenças psicosomáticas. O assédio moral é um fenômeno social com ampla importância atualmente, contudo, não se caracteriza como um fato novo, pois, sempre foi praticado em vários países. A presença do assédio moral no âmbito familiar em relação aos idosos é uma realidade latente, e precisa ser analisada.

Primeiramente se faz necessário, conceituar o fenômeno do assédio moral e entender cada um dos elementos que formam esse conceito: "Assediar" significa, perseguir, hostilizar, importunar, molestar. O adjetivo "moral" situa essa forma de assédio como algo relacionado à ética e oposto, em princípio, às moléstias físicas, adquirindo o significado de causa de sentimentos humilhantes, aviltantes e degradantes no sujeito assediado.(CARVALHO, 2009 p.03)

O assédio psíquico ou psicológico só ocorrerá nas hipóteses em que a conduta daquele que assedia gere em sua vítima um sentimento profundo de estresse, depressão ou trauma sendo necessário um tratamento psiquiátrico, o que, nem sempre ocorre, e que, portanto o assédio psíquico não se confunde com o assédio moral. (PEREZ, 2004 p. 03)

O assédio moral é uma forma de violação dos direitos da personalidade, é marcado pela sutileza das ações, é sempre bilateral, pois estão, de um lado, o assediado (vítima) e, de outro, o assediador, ambos vinculados por uma relação hierárquica ou de dominação deste último em relação ao primeiro. Trata-se de um modo de agir, individual ou coletivo, contínuo 


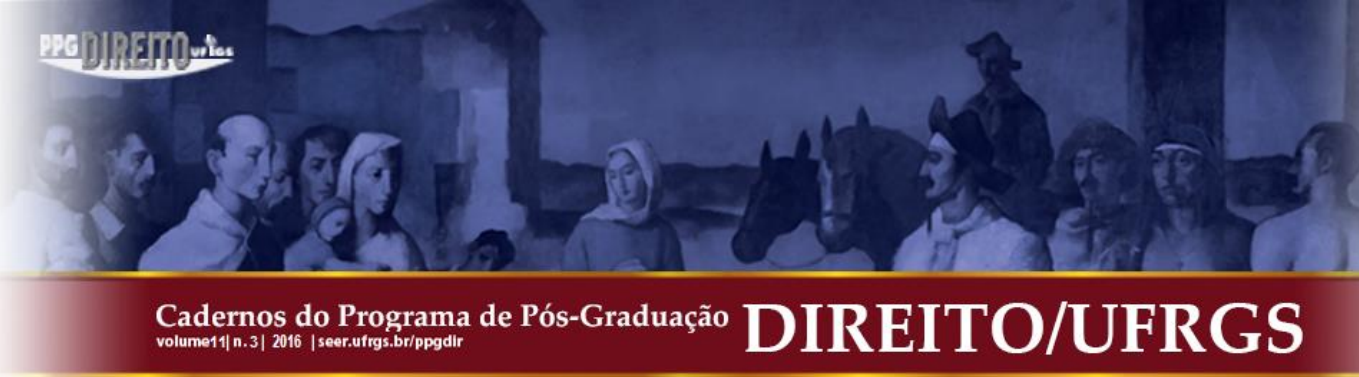

O Estado brasileiro nos últimos anos avançou consideravelmente em termos de saúde, previdência social, lazer e educação, no entanto, ainda existe muito a ser feito principalmente aos idosos.

O legislador ao criar o Estatuto do Idoso consagrou o direito de envelhecer como um direito da personalidade, sendo que os longevos já produziram em sua vida e muitos após a aposentadoria, por ser insignificante, continuam produzindo, e, portanto, merece a atenção do Estado, da sociedade e da família, merecendo receber atenção e respeito, para efetivar a máxima utilitarista de produzir felicidade.

O envelhecimento é um fenômeno social que requer a ação estatal, da sociedade e de suas instituições como forma de concretizar sua vivência digna. O envelhecimento humano é um dos únicos fatores naturais que interligam a todos; torna-se primordial o respeito à vida e à dignidade humana, e possibilitar aos idosos uma vida digna.

O assédio moral é uma forma de violação dos direitos da personalidade, é marcado pela sutileza das ações, é sempre bilateral, pois estão, de um lado, o assediado (vítima) e, de outro, o assediador, ambos vinculados por uma relação hierárquica ou de dominação deste último em relação ao primeiro. Trata-se de um modo de agir, individual ou coletivo, contínuo e repetitivo, que tende a violar os direitos da personalidade, atingindo a dignidade e, especialmente, a integridade psíquica da pessoa assediada, independentemente da ocorrência de um dano e da intencionalidade do agente individual ou coletivo.

O Estado garante ao longevo a proteção à sua dignidade por meio de normas, porém, nem sempre tais Direitos são tutelados, ou tem a eficácia necessária. A ausência de amor e afeto dos familiares, de estruturas hospitalares e de recreação e lazer pelo Estado, fere a dignidade do idoso, que sem esperança fica vulnerável às enfermidades físicas e da alma, perdendo a vontade de viver. Defender a dignidade do idoso e suas necessidades físicas e psíquicas é medida urgente, diante do tempo que escoa pelos dedos, em contagem regressiva.

O Direito de envelhecer com dignidade é um Direito da personalidade, e traz uma garantia de vida plena, um novo olhar para a vida no seu envelhecimento, tutelando o mundo interior e exterior do idoso, a proteção física e psíquica. 


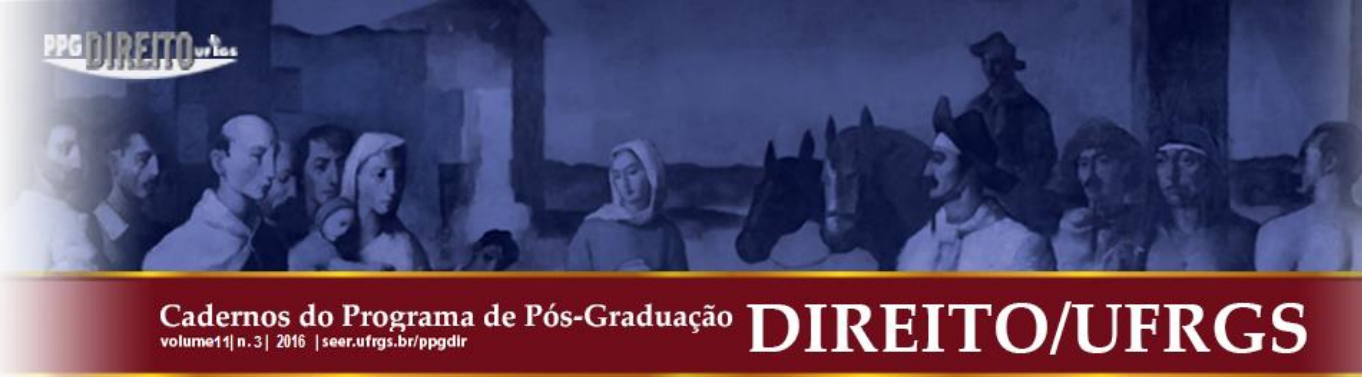

CUPIS, Adriano de. Os direitos da personalidade. 1.ed. Campinas, S.P.: Romana jurídica, 2004.

DE SOUZA, Rabindranath Valentino Aleixo. O direito geral de personalidade.Coimbra: Editora Coimbra, 1995.

DRAY, Guilherme Machado. Direitos de Personalidade: anotações ao Código Civil e ao Código do Trabalho. Coimbra: Almedina, 2006.

FARIAS, Edilsom Pereira. Colisão de Direito: A honra, a intimidade, a vida privada e a imagem versus a liberdade de expressão e informação. Sergio Antonio Fabris Editor. Porto Alegre, 2000.

FERMENTÃO, Cleide Aparecida Rodrigues Gomes; JÚNIOR, Paulo Gomes de Lima. A EFICÁCIA DO DIREITO À DIGNIDADE DA PESSOA HUMANA. Revista Jurídica Cesumar - Mestrado. v.12, n. 1, 2012, p. 313-340.

GAMA, Guilherme Calmon Nogueira da. Princípios constitucionais de direito de família: guarda compartilhada à luz da lei $\mathrm{n}^{\circ}$ 11.698/08: família, criança, adolescente e idoso. São Paulo: Atlas 2008.

GOMES, Andreia Sofia Esteves. A Dignidade da Pessoa Humana e o seu valor Jurídico Partindo da experiência constitucional portuguesa. In: MIRANDA, Jorge; SILVA, Marco Antonio Marques da (coordenação). Tratado Luso-Brasileiro da Dignidade Humana - São Paulo: Quartier Latin, 2009.

GOMES, Orlando apud SIMÓN, Sandra Lia. A proteção constitucional da intimidade e da vida privada do empregado. São Paulo. SP: LTr, 2000.

GONÇALVES, Diogo Costa. PESSOA E DIREITOS DE PERSONALIDADE: Fundamentação Ontológica da Tutela. Coimbra. Almedina: 2008.

HAYFLICK, Leonard. . Como e por que envelhecemos. 2. ed. Rio de Janeiro: Campus, 1997.

HIRIGOYEN, Marie-france Assédio Moral - A Violência Perversa no Cotidiano; tradução de Maria HELENA Kuhner. $9^{\circ}$ Ed. Rio de Janeiro: Bertrand Brasil, 2007.p. 109 


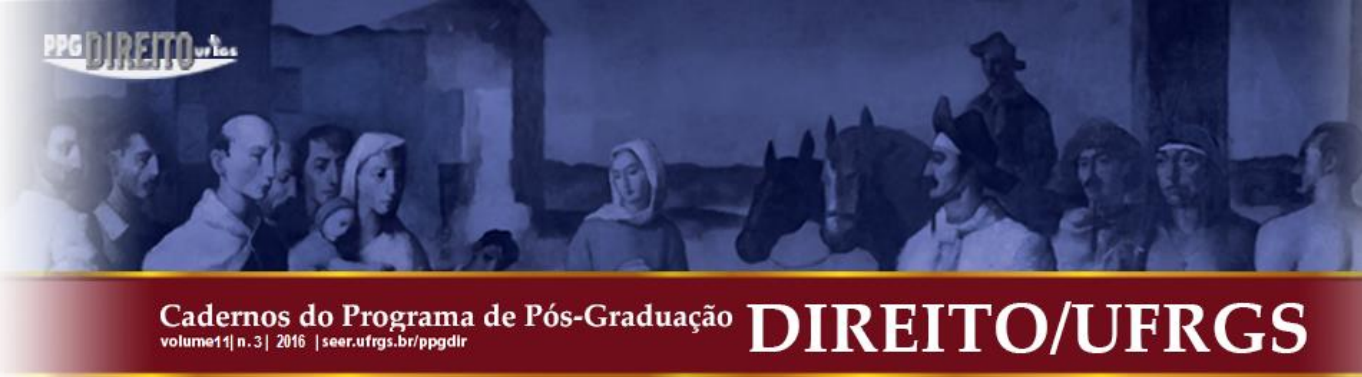

KANT Immanuel, Grundlegung zur Metaphysik der Sitten. Trad. de Paulo Quintela: Fundamentação da Metafisica dos Costumes. São Paulo: Abril Cultura, 1980, (Coleção "Os Pensadores”, dir. J.A. Motta Pesanha).

LISBOA, Roberto Senise. Manual de direito civil: direito de família e sucessões. 6 ed. São Paulo: Saraiva, 2010.

NUNES, Rizzato O principio Constitucional da Dignidade da Pessoa Humana. São Paulo, Editora Saraiva, 2002.

PÉREZ MACHÍO, A. I. Concreción del concepto jurídico de mobbing. Revista Electrónica de Ciencia Penal y Criminología, n. 6, 2004, p. 03. In: CARVALHO, Gisele Mendes. p. 3.

POSNER, Richard A.; SILVA, Evandro Ferreira e; MARI, Aníbal. A economia da justiça. São Paulo: WMF Martins Fontes, 2010.

SANTOS, Luciany Michelli Pereira dos. Assédio moral nas relações privadas: Uma proposta de sistematização sob a perspectiva dos direitos da personalidade e do bem jurídico integridade psíquica. 2005. Dissertação (Mestrado em Direito Civil) - Universidade Estadual de Maringá, p. 129.

SANTOS. Silva Sidney Costa. Envelhecimento visão de filósofos na antiguidade orienta e ocidental. Revista Rene. Fortaleza, v.2, n.1, 2001, p. 88-94.

SARLET, Ingo Wolfgang. Dignidade da pessoa humana e direitos fundamentais na Constituição Federal de 1988. 7. ed. Porto Alegre: Livraria do Advogado. 2009.

SILVA, De Plácido e. Vocábulo Jurídico. Atualização de Nagib Slaibi Filho e Gláucia Carvalho. 23. ed. Rio de Janeiro, RJ: 2003.

SZANIAWSKI, Elimar. Direitos de personalidade e sua tutela. 2.ed. São Paulo: Revista dos Tribunais, 2005.

TEIXEIRA, Ana Carolina Brochado; SÁ, Mária de Fátima Freire de. Envelhecendo com autonomia. In: FIUZA, César; SÁ, Maria de Fátima Freire de; NAVES, Bruno Torquato de Oliveira (Coord.). Direito civil: atualidades II: da autonomia privada nas situações jurídicas patrimoniais e existenciais. Belo Horizonte: Del Rey, 2007. p. 75-88. 


\section{adi)

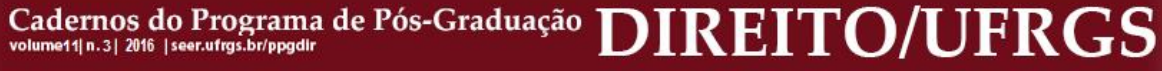

ZIMERMAN, Giute I. Velhice: aspectos biopsicossociais. Porto Alegre: Artmed, 2000.

Submissão: 01/08/2016

Aceito para Publicação: 02/12/2016 


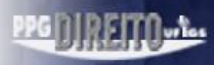

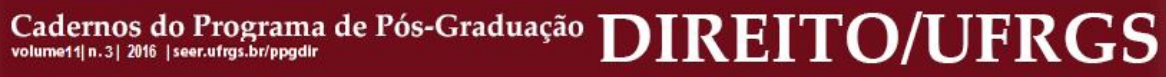

